\title{
1 Systematic analysis of 1,298 RNA-Seq samples and construction 2 of a comprehensive soybean (Glycine max) expression atlas
}

3 Fabricio Brum Machado ${ }^{1, \#}$, Kanhu C. Moharana ${ }^{1, \#, *}$, Fabricio Almeida-Silva ${ }^{1}$, Rajesh K. 4 Gazara $^{1}$, Francisnei Pedrosa-Silva ${ }^{1}$, Fernanda S. Coelho ${ }^{1}$, Clícia Grativol ${ }^{1}$, Thiago M. Venancio $^{1, *}$

$6 \quad{ }^{1}$ Laboratório de Química e Função de Proteínas e Peptídeos, Centro de Biociências e 7 Biotecnologia, Universidade Estadual do Norte Fluminense Darcy Ribeiro; Campos dos $8 \quad$ Goytacazes, Brazil. " These authors contributed equally to this work.

$11{ }^{*}$ Corresponding authors

12 Av. Alberto Lamego 2000 / P5 / 217; Parque Califórnia

13 Campos dos Goytacazes, RJ

14 Brazil

15 CEP: 28013-602

16 TMV: thiago.venancio@gmail.com; KCM: kcm.eid@gmail.com 


\section{Abstract}

21 Soybean (Glycine max [L.] Merr.) is a major crop in animal feed and human nutrition,

22 mainly for its rich protein and oil contents. The remarkable rise in soybean transcriptome

23 studies over the past five years generated an enormous amount of RNA-seq data,

24 encompassing various tissues, developmental conditions, and genotypes. In this study,

25 we have collected data from 1,298 publicly available soybean transcriptome samples,

26 processed the raw sequencing reads, and mapped them to the soybean reference

27 genome in a systematic fashion. We found that $94 \%$ of the annotated genes

$28(52,737 / 56,044)$ had detectable expression in at least one sample. Unsupervised

29 clustering revealed three major groups, comprising samples from aerial, underground,

30 and seed/seed-related parts. We found 452 genes with uniform and constant expression

31 levels, supporting their roles as housekeeping genes. On the other hand, 1,349 genes

32 showed heavily biased expression patterns towards particular tissues. A transcript-level

33 analysis revealed that $95 \%(70,963 / 74,490)$ of the known transcripts overlap with those

34 reported here, whereas 3,256 assembled transcripts represent potentially novel splicing

35 isoforms. The dataset compiled here constitute a new resource for the community, which

36 can be downloaded or accessed through a user-friendly web interface at

37 http://venanciogroup.uenf.br/resources/. This comprehensive transcriptome atlas will

38 likely accelerate research on soybean genetics and genomics. 


\section{Introduction}

41 Soybean (Glycine max [L.] Merr.) is one of the most important legume crops worldwide.

42 It is critically important in human nutrition, animal feed, and biotechnological

43 applications. Global climate change and increased food demand resulting from a growing

44 human population have been fueling the development and application of

45 biotechnological methods to generate better cultivars (lizumi et al., 2014). In recent years,

46 various omics approaches have been deployed to improve productivity of several crops,

47 including soybean. An important achievement in soybean omics-based research was the

48 availability of whole-genome sequencing data, which helped identify molecular markers

49 (e.g. single nucleotide polymorphisms, SNPs) (Schmutz et al., 2010; Deshmukh et al., 2014)

50 that are instrumental in the identification of genes associated with various phenotypes of

51 interest. Further, the soybean whole-genome sequencing project has also contributed to

52 the substantial rise in soybean transcriptome studies (Libault et al., 2010;Severin et al.,

53 2010;Garg and Jain, 2013;O'Rourke et al., 2017), initially dominated by microarray

54 platforms and later by RNA-Seq technologies.

55 To date, several studies reported spatiotemporal changes occurring in various soybean tissues using RNA-seq. The two first soybean RNA-Seq studies were published by Libault et al. (Libault et al., 2010) and Severin et al. (Severin et al., 2010). The former reported the sequencing of 14 (mainly root and nodule) tissues, whereas the latter evaluated several tissues and seed developmental stages. Dozens of other studies followed, such as those addressing different life cycle stages (Jones and Vodkin, 2013;Bellieny-Rabelo et al., 2016;Gazara et al., 2019), conditions (Belamkar et al., 2014), and cultivars/lines (Goettel et al., 2014). The accumulation of plant transcriptomic data in public repositories [e.g. Sequence Read Archive (SRA) at the National Center for Biotechnology Information (NCBI)] inspired the development of unified collections or atlases, such as those found for Arabidopsis thaliana (Fucile et al., 2011), Medicago truncatula (He et al., 2009), Gl. max (Supplementary Table S1), as well as multi-species atlases (Dash et al., 2012), which are often reused by the scientific community. Specifically in soybean, Kim et al. constructed the SoyNet (www.inetbio.org/soynet) database using 734 microarrays and 290 RNA-seq samples (Kim et al., 2017), while Wu et al. uncovered a nodulation-related co-expression module by analyzing 1,270 microarray samples generated with Affymetrix gene chips (Wu et al., 2019).

Despite the previous efforts to integrate soybean transcriptomes, there is a massive amount of soybean RNA-Seq data that remain largely unexplored. Here, we have collected data from 1,298 publicly available soybean RNA-seq samples from the NCBI SRA database. We systematically processed and mapped sequencing reads to the soybean reference genome. Transcriptional levels were estimated to allow a systematic global gene expression analysis, aiming to elucidate the dynamics of transcriptional regulation 
78 across this broad range of samples, tissues, and cultivars. Further, the collected and

79 processed data are readily available to allow both, automatic analysis and single-gene

80 investigations using an easy-to-use interface at our lab website

81 (http://venanciogroup.uenf.br/resources/).

82

RESULTS AND DISCUSSION

Data gathering, processing, and mapping to the reference genome reveal an overall high quality of the publicly available soybean RNA-Seq data

We performed an extensive literature mining process to gather as many as possible soybean RNA-seq datasets. A total of 1,742 raw read sequencing files were downloaded from the NCBI SRA database (Supplementary Table S2). Reads obtained from the same biological sample were combined in a single FASTQ file (or in two files, for paired-end data; *_1.fq and *_2.fq). This resulted in 1,298 samples (65\% single-end and 35\% pairedend) from 84 BioProjects comprising sixteen different broad tissue categories in various developmental stages (Supplementary Table S3). Approximately 35\% (458/1298) of the samples lacked cultivar/genotype information in SRA. Among the other 840 samples, we found 157 different soybean cultivar names, although this is likely an overestimation because of authors calling the same cultivars with slightly different names during data submission. The cultivar Williams 82 , which had the genome sequenced, represented $23 \%$ $(302 / 1,298)$ of the total samples. Leaves were the most abundant tissue, representing $46 \%(603 / 1,298)$ of the samples (Figure 1). Three libraries from unknown tissue sources were excluded. We have also found that $76 \%(986 / 1,295)$ of the libraries were unstranded (Supplementary Table S3).

Reads from each RNA-seq library were mapped to the reference genome, assembled, and used for estimating gene expression (Figure 2). Whenever present, adapter sequences were trimmed. Reads with average quality lower than 20 were excluded. An average of 32,210,805 million reads pairs per sample with paired-end data and 29,579,316 million reads per sample with single-end data were used for read mapping. Mapped and uniquely mapped reads correspond to an average of $87.9 \%$ and $81 \%$, respectively (Supplementary Table S4 and Supplementary Figure 1). Further, we excluded 47 samples for which: i) $50 \%$ or more of the reads failed to map or; ii) $40 \%$ or more of the reads failed to uniquely map. After these exclusions, 1,248 samples were kept for further downstream analysis.

Several methods used to analyze RNA-seq data (e.g. differential gene expression) rely on read count normalization strategies (Robinson and Oshlack, 2010;Po-Yen et al., 113 2011), such as Reads Per Kilobase Million (RPKM) (Mortazavi et al., 2008), Fragments Per 114 Kilobase Million (FPKM), and Transcripts Per Million (TPM) (Wagner et al., 2012), out of 115 which the latter has been proposed to be more consistent across technical replicates 
116 (Wagner et al., 2012;Conesa et al., 2016; Li and Li, 2018). Here, we normalized data using

117 TPM for most of the downstream analysis. Nevertheless, $\log _{2}$ transformed raw read

118 counts are more commonly used for quality control steps such as unsupervised sample

119 clustering (Jordan et al., 2015). In addition, many popular tools used for differential gene

120 expression analysis (e.g. DESeq2, edgeR) require raw read counts instead of normalized

121 read counts. Therefore, after read mapping, we estimated transcript abundances in the

122 form of raw read counts per transcript and TPM. Transcript-level expression values were

123 also aggregated to estimate expression at gene level. Gene expression values across 1,248

124 samples were then used in further downstream analysis.

126 Unsupervised sample clustering reveals three major clades comprising underground,

127 aerial, and seed tissues

128 In transcriptomics studies, gene and samples are often clustered to identify sub-groups

129 with similar transcriptional profiles (Liu and Si, 2014;Marini and Binder, 2019). While gene

130 clustering helps identify co-expressed genes, sample clustering is instrumental to detect

131 broad transcriptional similarities between samples, as well as to identify potential

132 technical artifacts and mislabeled samples. Among several methods, distance-based

133 hierarchical clustering, K-means clustering, and dimensional-reduction-based

134 visualization methods (e.g. principal component analysis, PCA) are commonly used.

135 Recently, t-Distributed Stochastic Neighbor Embedding (t-SNE) has been shown to

136 provide a better global structure of sample sub-groups than several other methods (Dey

137 et al., 2017). Here, we employed three sample clustering methods to identify outliers and

138 overall pairwise sample similarity. We used a gene expression matrix as input to perform

139 hierarchical clustering, $K$-means clustering, and t-SNE analysis. These analyses uncovered

140 three major groups comprising samples from aerial, underground, and developmental or

141 seed tissues (Figure 3) (Severin et al., 2010). Interestingly, however, we found an

142 additional cluster comprising samples from leaves and shoots from drought-stress-

143 related and leaf senescence samples. Although not entirely novel, these results are part

144 of an important step to check for technical issues or biases that could, for example, result

145 in the clustering of samples from the same sequencing batch or research group. Four

146 shoot samples and one root sample clustered with seed-embryo samples. After

147 confirming this result with the t-SNE and $K$-means clustering, we excluded these samples.

148 Overall, sample clustering supports a high quality level of the publicly available RNA-Seq

149 samples analyzed here, as only $0.4 \%$ (5/1248) of the samples were excluded after the

150 clustering analysis. 
152 Systematic analysis of hundreds of RNA-Seq libraries support the expression of the 153 vast majority of the soybean genes

154 After comparing the reference transcript annotations (for 56,044 genes) with the 155 merged consensus transcript assembly, we excluded $1.3 \%(759 / 56,044)$ of the genes 156 because of overlapping gene predictions. Next, we applied a minimum TPM threshold of

1571 to define a gene as expressed and found that $92.1 \%(51,644 / 56,044)$ of the known 158 soybean protein-coding genes were expressed in at least one sample. The remaining 159 genes had their TPM values set to zero and classified as not expressed. An average of 16031,063 genes were expressed per sample. The tissues with the greatest numbers of 161 expressed genes were inflorescence (37,108 genes) and flower (average of 36,051 genes) 162 (Supplementary Figure 2A), whereas nodules had the lowest number of expressed genes 163 (average of 25,718 genes). We also found 16,916 genes expressed in at least 1,150 164 samples (Supplementary Figure 2B), including 1,758 genes that are expressed in all 1,243 165 samples. On the other hand, $6 \%(3,233 / 56,044)$ of the genes were not expressed (TPM < 1661 ) in any sample, out of which $82 \%$ had coding regions comprising less than 500 codons 167 (Supplementary Figure 3). As a final data quality check, we analyzed the top 1,000 168 expressed genes from each tissue category using MapMan pathway bins (see Methods). 169 For example, contrasting gene expression profiles of roots and leaves uncovered several 170 expected transcriptional patterns of photosynthesis genes in the latter (Supplementary 171 Figure 4).

\section{Housekeeping genes}

174 Given the wide coverage of tissues and conditions, we also sought to identify 175 housekeeping (HK) genes based on the assumption that these genes are constitutively 176 and robustly expressed across broad conditions (Czechowski et al., 2005; Hu et al., 2009). 177 Further, several of these genes have also been used as references in real-time 178 quantitative polymerase chain reaction (RT-qPCR) assays (Supplementary Table S5). 179 Hence, by using a large collection of RNA-Seq datasets as the one presented here, one 180 can not only evaluate commonly used reference genes, but also propose new ones. By 181 employing a previously developed method (Hoang et al., 2017), we inferred 452 HK genes 182 (Supplementary Table S6). We evaluated expression levels of each gene in tissues with at 183 least 10 samples and found that HK genes had very low expression variation (Figure 4A). 184 To identify HK genes, we used a score that consists of the product of the Coefficient of 185 Variation and ratio of the maximum to the minimum expression level (see methods for 186 details). Genes with scores within the 1st quartile were classified as HK genes. Further, 
187 we used a tissue-specificity index Tau ( $\tau$ ) (Yanai et al., 2004;Kryuchkova-Mostacci and 188 Robinson-Rechavi, 2017) to estimate tissue specificity and verify whether our predicted 189 HK genes were broadly expressed or not. The $\tau$ values scale from 0 to 1 , where low and 190 high values indicate widely expressed and more tissue-specific genes, respectively. The $\tau$ 191 scores of the HK genes ranged from 0.053 to 0.379 , supporting their stable expression 192 level (Figure 6).

193 According to their expression levels, HK genes were grouped in three broad 194 clusters (Figure 4B). Importantly, 7 previously proposed HK genes (Yim et al., 2015) were 195 present in our list (Figure 4), out of which four (ACT11.C, B-actin, CYP.B and, ELF1 $\alpha$ ) belong 196 to cluster 1 (highly expressed, Figure 4A), confirming that high expression is typically an 197 important factor in choosing reference genes. Conversely, given its expression 198 fluctuations (Figure 4), we do not recommend using UBQ10, which has also been proposed as a reference gene.

200 Pathway enrichment analysis of the 452 putative HK genes revealed that these 201 genes are involved in various biological processes such as RNA degradation, mRNA 202 surveillance, and TCA cycle (Figure 4B). We found an enrichment of orthologs of 203 Arabidopsis essential genes (Meinke, 2019) among the HK genes (Fisher's Exact test; p204 value $=1.76 \mathrm{e}-2$ ). Given their roles in basic biological processes, we also verified the 205 conservation of the HK genes in other 14 species on Phytomine and found that $85 \%$ 206 (385/452) of them have orthologs in at least 10 other species (Supplementary Table S6), 207 as opposed to an average of $181.6( \pm 11.6)$ in 5 random lists of 452 non-HK genes.

\section{Tissue-specific gene expression}

210 We compared the global expression patterns between tissues to identify tissue-specific genes (Figure 5). We selected 359 samples that belong to the same tissues and clustered together (Supplementary Table S7), which resulted in the exclusion of four tissue categories. The 12 tissues were compared with each other (a total of 144 comparisons), resulting in a total of 1,349 genes up-regulated in a single tissue as compared to all the others (Figure 7; Supplementary Table S8). Importantly, $96 \%$ of these genes $(1,300 / 1,349)$ had $\tau$ indexes greater than 0.8 and median $\tau$ of 0.9704 (Figure 6). Given their strong preferential expression in particular tissues, we called these genes as tissue-specific.

The number of tissue-specific genes ranged from 4 in pods to 358 in nodules.

220 tissue-specific genes. The lower number of tissue-specific genes in leaf, shoot, cotyledon, 221 and pod can be explained by the physiological or developmental relatedness of some 222 samples (e.g. cotyledon and seed). Notably, $39 \%(520 / 1,349)$ of the tissue-specific genes 223 identified here were also identified by Severin et. al (Severin et al., 2010) using a much 
224 smaller set of samples, supporting the general high quality and reproducibility of the

225 publicly available soybean transcriptomes. Strikingly, nearly $12 \%(168 / 1,349)$ of the

226 tissue-specific genes were transcription factors (TFs) (Table 1), which is a remarkable

227 enrichment (Fisher's Exact Test, $\mathrm{p}$-value $=2.94 \mathrm{e}-11$ ) considering the overall abundance of

228 TFs in the soybean genome (Moharana and Venancio, 2019). Among the tissue-specific

229 TFs, 27, 21, and 20 genes belong to the MYB, $\mathrm{C} 2 \mathrm{H} 2$, and ERF families, respectively. Of the

23027 MYB TFs, 20 were specific to flower $(n=8)$, hypocotyl $(n=7)$, and endosperm $(n=5)$. Of

231 the $21 \mathrm{C} 2 \mathrm{H} 2$ genes, 12 were specific to nodule $(n=6)$ and endosperm $(n=6)$. Ten out of 20

232 ERF genes and six out of 10 WRKY genes were specific to hypocotyl. Finally, 8 of 9 MIKC

233 type MADS TFs were flower-specific. Several interesting tissue-specific genes are

234 discussed in the sections below.

235

236 Nodule-specific genes

237 Symbiotic $\mathrm{N}_{2}$ fixation takes place in root nodules of several Fabaceae species. Nodulation

238 had a single origin in the common ancestor of the $\mathrm{N}_{2}$-fixing clade, followed by multiple

239 independent losses (Griesmann et al., 2018). Among the genes lost in non-nodulating

240 species, Nodule Inception (NIN) and Rhizobium-Directed Polar Growth (RPG) were

241 reported to be of paramount importance for the origin of root nodules (Griesmann et al.,

242 2018). As mentioned above, nodule is the tissue with the greatest number of tissue-

243 specific genes in soybean, a trend that has also been reported in other legumes (Benedito

244 et al., 2008). Soybean nodules have been shown to correlate poorly with other tissues at

245 the transcriptional level (Severin et al., 2010), a finding that we corroborated here.

We found several nitrogen fixation genes as nodule-specific, including two 248 families mostly represented among the 29 nodule-specific TFs were NIN-like $(n=6)$ and $249 \mathrm{C} 2 \mathrm{H} 2(\mathrm{n}=6)$. A higher percentage of $\mathrm{NIN}$-like and $\mathrm{C} 2 \mathrm{H} 2$ nodule-specific TFs have been also 250 described previously (Libault et al., 2010;Severin et al., 2010). Importantly, NIN-like and $251 \mathrm{C} 2 \mathrm{H} 2$ TFs are important in nitrate signaling (Konishi and Yanagisawa, 2013) and 252 symbiosome differentiation during nodule development (Sinharoy et al., 2013). We also 253 found three nodule-specific ERF TFs that are conserved in Phaseolus vulgaris and 254 Medicago truncatula and are essential for nodule differentiation and development 255 (Vernié et al., 2008).

We found 12 soybean nodule-specific genes within the experimentally validated 257 list of over 200 nodulins described previously (Roy et al., 2019). These 12 genes include 258 the above mentioned ERF TFs, NIN (Glyma.04G000600), C2H2 (Glyma.07G135800), and 259 GRAS (Glyma.16G008200). Next, we analyzed the 28 genes from a nodule-related module 260 identified in a co-expression network derived from soybean microarray data (Wu et al., 
261 2019). Notably, 9 of these 28 genes were identified as nodule-specific in our analysis: one

262 leghemoglobin (Glyma.10G199000), two NIN-like TFs (Glyma.02G311000,

263 Glyma.14G001600), two purine biosynthesis genes (Glyma.08G001000,

264 Glyma.11G221100), one iron transporter (Glyma.05G121600), one zinc finger protein-

265 related (Glyma.08G044700), one sulfate transporter (Glyma.18G018900), and a formyl

266 transferase (Glyma.19G115900).

\section{Endosperm-specific genes}

269 The endosperm plays important roles during seed development. Ar. thaliana endosperm270 specific genes are associated with cell cycle, DNA processing, chromatin assembly, protein 271 synthesis, cytoskeleton- and microtubule-related processes, and cell/organelle 272 biogenesis and organization (Day et al., 2008). Out of the 301 endosperm-specific genes 273 reported here, 9 (Glyma.19G040600, Glyma.09G194500, Glyma.01G147300, 274 Glyma.19G058100, Glyma.19G044000, Glyma.04G187100, Glyma.03G219800, 275 Glyma.02G255900, and Glyma.08G129200) encode chromatin modifiers such as histone 276 acetyltransferases, histone-lysine n-methyltransferases, histone deacetylases, and 277 histone demethylases. Further, 17 endosperm-specific genes encode F-box proteins and 2788 genes encode BTB-POZ and MATH domain proteins, which likely operate in the 279 ubiquitin-proteasome pathway (Smalle and Vierstra, 2004;Figueroa, 2005). We also found 28036 endosperm-specific TFs, including 6 and $5 \mathrm{C} 2 \mathrm{H} 2$ and MYB TFs, respectively. Together, 281 these results clearly show a number of endosperm-specific genes as involved in 282 transcriptional and post-transcriptional regulatory processes.

Flower-specific genes

285 The genetic basis of floral development has been widely studied in several plants, 286 including Ar. thaliana and Antirrhinum majus (Soltis et al., 2007;Bowman et al., 2012). 287 According to the ABCDE model, most of the genes involved in the regulation of flower 288 development encode MADS and AP2/ERF TFs (Chi et al., 2017). The combinatory action 289 of these genes regulates the development of various distinct floral parts. For example, $A r$. 290 thaliana sepal development is regulated by the MADS-box gene APETALA1 (AP1) together 291 with the ERF TF APETALA2 (AP2). Similarly, two MADS-box genes, APETALA3 (AP3) and 292 PISTILLATA (PI), regulate petal/stamen development, whereas the MADS-box gene 293 AGAMOUS (AG) regulates carpel development. These basic regulators of flower 294 development are also conserved in other angiosperms (Becker, 2003;Zhao et al., 2017). 295 Further, 491 genes have been suggested to be involved in soybean flower development 296 (Jung et al., 2012). 
Recently, several studies reported transcriptional changes during flowering time in legumes (Weller and Ortega, 2015). We found 182 flower-specific genes, including at least 20 members of the plant invertase/pectin methylesterase inhibitor (PMEI) superfamily, which is involved in cell wall modification in Ar. thaliana (Zhao et al., 2015). Specific PMEls are highly expressed in specific wheat floral parts, such as anthers and pollen tubes (Rocchi et al., 2012), playing a significant role in flower development (Wormit and Usadel, 2018). In addition, we found 20 flower-specific TFs, mostly from the MYB $(40 \%, 8 / 20)$ and MIKC-type MADS (40\%, 8/20) families. Finally, out of 8 these MIKC genes, two AGAMOUS-like (Glyma.03G019400, Glyma.07G081300) and three PISTILLATA (Glyma.06G117600, Glyma.13G034100, Glyma.14G155100) were among the 36 flowerspecific genes reported by Jung et al. (Jung et al., 2012).

\section{Identification of novel transcripts}

We compared the genomic coordinates of the transcripts assembled in our atlas with those available in Phytozome and categorized them in nine classes (Table 2). We found that $95 \%(70,963 / 74,490)$ of the transcripts precisely matched known transcripts (class =). We also investigated class-J and class- $U$ categories, which account for 3,256 and 23 transcripts, respectively. Class-J comprises multi-exon transcripts with at least one known exon junction, while class- $U$ encompasses transcripts located in intergenic regions. While class-J transcripts include new isoforms of known genes, those from class- $U$ are useful to identify potentially new genes. We found that 30\% (983/3256) of the class-J transcripts and $17 \%(4 / 23)$ of the class-U transcripts had TPM $\geq 1$ in 907 and 1,207 samples, respectively. Only one of the four class-U expressed transcripts (TU4871, Chr02:12125821-12127123) encode a protein longer than 50 aa, which contains a reverse transcriptase-like RNase_H (PF13456) domain, supporting that it is likely a mobile element. In two of these expressed class-U transcripts (TU28093, TU56508), only one exon showed high read coverage (Supplementary Figure 5).

All the 3,256 class-J transcripts were further analyzed for alternate splicing (AS) events using ASprofile (Florea et al., 2013). AS events were categorized in one of six categories: (i) exon-skipping; (ii) multiple exon-skipping; (iii) alternative transcription start site (TSS); (iv) alternative transcription termination sites (TTS); (v) intron retention and; (vi) alternate 5' and/or 3' exon ends. We detected 6,582 AS events, mostly TSS and TTS (Table 3). Several novel AS events were supported by hundreds of split reads (Supplementary Figure 6-8). For example, TU62356 from Glyma.17G195900 (CASEIN KINASE 1-LIKE PROTEIN 4) is a novel isoform with a skipped exon (Supplementary Figure 6). Interestingly, we found no support for this alternative isoform in other tissues. 


\section{Data availability through a user-friendly web interface}

335 We developed a simple user-friendly web interface to allow researchers to easily explore 3361,243 soybean transcriptome samples. Through this interface (Figure 8), one can explore 337 the expression of a particular gene in multiple tissues, with the aid of an image illustrating 338 all the available tissues. Alternatively, users can also retrieve expression profiles of 339 multiple genes in batch, with multiple filtering options (e.g. by tissue, BioProject, study). 340 The outputs can be exported as plain text files. We strongly believe that this website will 341 optimize data reuse and help research groups in their own projects. This service can be 342 freely accessed at http://venanciogroup.uenf.br/resources/.

\section{Conclusions}

345 We have culled a large collection of publicly available RNA-seq datasets to construct a 346 transcriptome atlas in soybean. We implemented a pipeline with state-of-art methods to 347 map and quantify gene expression levels in 16 different broad tissue categories. This atlas 348 allowed us to identify constitutive and tissue-specific genes. The constitutively expressed 349 genes might, for example, be used as reference genes in RT-qPCR experiments, whereas 350 tissue-specific genes might help scientists test hypotheses in downstream experiments 351 and functional genomics studies. To optimize data reuse, we elaborated a simple web 352 interface to allow the community to quickly access and browse the collected data. We 353 believe this atlas will be an invaluable resource not only for basic research projects, but 354 also in the development of novel strategies to improve soybean productivity to meet 355 increasing global food demands.

\section{Methods}

\section{Soybean genome and annotation data}

359 Soybean genomic sequences and gene annotation data (assembly version:

360 Gmax_275_Wm82.a2.v1) were obtained from Phytozome (Schmutz et al., $3612010 ; G o o d s t e i n$ et al., 2012). The gene annotation file contained 56,044 and 88,647 genes 362 and transcripts, respectively. The gene annotation file containing exon-intron boundaries 363 (GFF3 format) was used as a reference guide in read mapping. We excluded 759 364 overlapping genes from the analysis. The gene description file was used to obtain various 365 annotations such as GO, KEGG, KOG, and Arabidopsis ortholog descriptions.

\section{Soybean RNA-Seq data}

368 To identify soybean transcriptome sequencing projects, we searched the NCBI SRA 369 database (https://www.ncbi.nlm.nih.gov/sra) and the metadata were exported by using 
370 Run selector (https://trace.ncbi.nlm.nih.gov/Traces/study/). We also searched Soybean

371 RNA-seq studies in the literature (up to May 2018) to find additional datasets. We

372 enriched this list of studies with various other details, such as PubMed ID and experiment

373 details obtained by using NCBI e-fetch. Using these metadata, we excluded miRNA/siRNA

374 samples and a few other samples showing technical issues such as: i) empty FASTQ files;

375 ii) paired-end samples with single-end reads and; iii) paired-end reads of unequal lengths.

376 Collectively, we downloaded a total of 1,742 .sra files (Supplementary table S2), which

377 were decompressed using sra-toolkit (v.2.5.7) (Leinonen et al., 2010).

379 Preprocessing and quality control

380 Quality assessment of FASTQ files was performed using FASTQC 381 (https://www.bioinformatics.babraham.ac.uk/projects/fastqc/). Datasets were 382 processed using Trimmomatic (v0.36) (Bolger et al., 2014) to remove reads with average 383 base quality lower than 20 or containing adapter sequences. Library strandedness was 384 determined with the infer_experiment.py script from RSeQC (Wang et al., 2012) using a 385 mapping of $20 \%$ of the reads of each sample to the soybean genome in a fast-forward 386 manner using Bowtie2 (Langmead and Salzberg, 2012).

Transcript assembly and gene expression estimation

389 We aligned the reads to the Gl. max reference genome (Gmax_275_Wm82.a2.v1) by using STAR (v.2.5.3a) (Dobin et al., 2013) with default parameters, along with the soybean gene annotation file containing exon-intron boundaries (in GFF3). When required, STAR also splits reads to find novel exon-intron boundaries or splice sites. The log files were processed to obtain read mapping statistics. Next, StringTie (v. 1.3.4) (Pertea et al., 2015) was used to assemble transcripts and estimate normalized gene expression. We performed transcriptome assemblies for each of the 16 tissues separately. In StringTie, we set the following parameters: i) at least 5 reads with at least $25 \%$ of the total read length covering both sides of an exon junction boundary (-j 5 -a $0.25 *$ read_length); ii) average read depth for a transcript of at least 10 (-c 10) and; iii) library strandedness, when applicable. The resulting 16 assembled transcript annotations from each tissue were combined with TACO v0.7.3 (Niknafs et al., 2017). GffCompare (v0.10.5) (https://ccb.jhu.edu/software/stringtie/gffcompare.shtml) was used to compare assembled and reference transcripts. Further, featureCount (subread-v1.6.2) (Liao et al., 2014) was used to count the number of reads per feature at transcript and gene levels, 405 


\section{Sample clustering}

407 We assessed the sample clustering patterns by submitting 41,011 genes with mean $\log _{2}$ 408 (read count+1) $\geq 1$ to: i) hierarchical clustering; ii) t-SNE clustering and; iii) $K$-means 409 clustering. These analyses were performed using R functions (www.r-project.org) cor(), 410 hclust(), and kmeans(). For t-SNE clustering, we used the $t$-SNE R package (Krijthe, 2015) 411 with clustering parameters max_iter $=5000$ and perplexity= 50. For hierarchical clustering, 412 sample dissimilarity (1 - Pearson Correlation Coefficients) values were used to infer 413 pairwise sample distances. The resulting tree was inspected for unexpected sample 414 clustering patterns. t-SNE separated samples in 35 sub-clusters. Thus, we ran the $K$-means 415 clustering analysis to find 35 centroids ( $k=35)$.

\section{Identification of novel genes and splicing isoforms}

418 To identify novel genes and isoforms, we analyzed the GffCompare output files. 419 Transcripts not overlapping with any known reference transcript were assigned to class$420 \mathrm{U}$. The nucleotide sequences of the class $U$ transcripts were extracted and translated 421 using TransDecoder (v. 3.0.1). Protein domains were predicted using HMMER3 v. 3.1b2 422 (all default parameters except domain e-value < 0.01) (hmmer.org) and the Pfam 423 database (release 32.0) (El-Gebali et al., 2019). Read coverage of these novel genes were 424 visualized with Gbrowse, available on Soybase 425 (https://soybase.org/gb2/gbrowse/gmax2.0). Class-J transcripts were classified as 426 putative novel isoforms. Splice junctions of these transcripts in GTF format were 427 compared against all known splice junctions using ASprofile v.b-1.0.4 (Florea et al., 2013). 428 The number of reads supporting a splice junction was visualized as sashimi plots using 429 Integrated Genome Viewer (v2.4.10)(Robinson et al., 2011).

\section{Analysis of the top $\mathbf{1 0 0 0}$ highest expressed gene lists}

432 The top 1000 genes with the greatest average TPM in each tissue category were analyzed 433 using MapMan (v3.5.1R2) (Thimm et al., 2004). To assign pathway bins, amino acid 434 sequences of these gene lists were compared against Arabidopsis peptide database using 435 Mercator4 (v. 2.0) (Schwacke et al., 2019).

\section{Identification of housekeeping genes}

438 We selected 11 tissues with at least 10 samples, which resulted in a total of 1,225 samples. 439 The variability in gene expression was evaluated as previously described (Hoang et al., 440 2017). The following criteria were applied to identify HK genes: 
i. A gene with TPM $<1$ in a given sample was considered as not expressed (these TPM values were set to 0 );

ii. Genes must be expressed in all 1,225 samples. This step resulted in 1,809 genes;

iii. The mean TPM of each gene was calculated by taking the average of the gene expression across all samples;

iv. The Coefficient of Variation (CoV) was computed by taking the standard deviation divided by the mean expression of a gene;

v. The ratio of the maximum to minimum (MFC) was calculated by dividing the largest by the smallest TPM value. A product score (MFC-CoV) was calculated based on the product of CoV and MFC for each gene;

vi. Genes with MFC-CoV scores within the $1^{\text {st }}$ quartile were classified as HK genes.

HK genes were also analyzed using the tissue-specificity index $\tau$ (Yanai et al., 2004;Kryuchkova-Mostacci and Robinson-Rechavi, 2017). The $\tau$ values ranged from 0 (broad expression) to 1 (exclusive expression). $\tau$ for each gene was calculated by using the formula:

where

$$
\tau=\frac{\sum_{i=1}^{n}\left(1-\hat{x}_{i}\right)}{n-1} ; \hat{x}_{i}=\frac{x_{i}}{\max _{1 \leq i \leq n}\left(x_{i}\right)}
$$

$x_{i}=$ expression of the gene in tissue $i$.

$n=$ number of tissues.

\section{Assessment of tissue-specific expression}

We used the $\log _{2}$ transformed TPM values for this analysis. Each of the 12 tissues was compared against each other (a total of 144 comparisons) to find significantly overexpressed genes using limma (Ritchie et al., 2015). We used $\log _{2}$ (fold-change) $\geq 2$ and adjusted $\mathrm{p}$-value $\leq 0.05$ (moderated t-statistic) to identify significantly over-expressed genes. If a gene $G$ is over-expressed in a tissue $T$ in comparison to the other 11 tissues, $G$ was considered as specifically expressed in $T$. We also used $\tau$ to assess tissue-specific expression by applying a minimum threshold of 0.8 , as previously recommended (Kryuchkova-Mostacci and Robinson-Rechavi, 2017).

\section{Gene orthologs and enrichment tests}

We obtained the gene descriptions from Phytomine (https://phytozome.jgi.doe.gov/phytomine/begin.do), which is an InterMine (Lyne et al., 
477 2015) interface to genomic data from Phytozome (Goodstein et al., 2012). We used

478 Phytomine to assess the conservation of HK genes in 14 different species (Ph. vulgaris,

479 Me. truncatula, Vigna unguiculata, Ar. thaliana, Oryza sativa, Gossypium raimondii,

480 Carica papaya, Vitis vinifera, Sorghum bicolor, Zea mays, Amborella trichopoda,

481 Selaginella moellendorffii, Physcomitrella. Patens, and Volvox carteri). To estimate the

482 conservation of non-HK genes, we created 5 sets of 452 randomly selected genes from

483 the 55,592 non-HK genes. Each of these sets were searched for orthologs in the above

484 mentioned 14 species. GO enrichment was performed on Phytomine (corrected p-value

485 < 0.05). We performed Kyoto Encyclopedia of Genes and Genomes (KEGG) pathway 486 enrichment using KOBAS 3.0 (Ai and Kong, 2018). We used the Fisher's Exact test to assess

487 the enrichment of essential genes and TFs in particular gene sets. The list of 510 488 Arabidopsis EMBRYO-DEFECTIVE (EMB) genes (Meinke, 2019) were searched on 489 Phytomine and the corresponding 1,010 soybean orthologs were retrieved. The list of 490 soybean TFs was obtained from a recently published work (Moharana and Venancio, 491 2019).

\section{Web server}

494 The TPM and read count values for 54,877 genes across 1243 samples were stored in a 495 relational database implemented in MySQL and hosted on an Apache HTTP web server. 496 The front-end to this database was developed using Python/html/CSS. Interactive 497 visualizations were implemented using D3.js (https://d3js.org/) and Plotly.js 498 (https://plot.ly/) javascript libraries. The online server is publicly available at 499 http://venanciogroup.uenf.br/resources/.

\section{Acknowledgements}

502 This work was supported by Fundação Carlos Chagas Filho de Amparo à Pesquisa do 503 Estado do Rio de Janeiro (FAPERJ; grants E-26/010.002019/2014, E-26/102.259/2013, and 504 E-26/203.014/2018), Coordenação de Aperfeiçoamento de Pessoal de Nível Superior 505 Brasil (CAPES; Finance Code 001), and Conselho Nacional de Desenvolvimento Científico 506 e Tecnológico (CNPq). The funding agencies had no role in the design of the study and 507 collection, analysis, and interpretation of data and in writing.

\section{References}

$510 \mathrm{Ai}, \mathrm{C}$, and Kong, L. (2018). CGPS: A machine learning-based approach integrating multiple gene set analysis tools for better prioritization of biologically relevant pathways. Journal of Genetics and Genomics 45, 489-504.10.1016/j.jgg.2018.08.002 
Becker, A. (2003). The major clades of MADS-box genes and their role in the development and evolution of flowering plants. Molecular Phylogenetics and Evolution 29, 464489.10.1016/s1055-7903(03)00207-0

Belamkar, V., Weeks, N.T., Bharti, A.K., Farmer, A.D., Graham, M.A., and Cannon, S.B. (2014). Comprehensive characterization and RNA-Seq profiling of the HD-Zip transcription factor family in soybean (Glycine max) during dehydration and salt stress. BMC Genomics 15, 950.10.1186/1471-2164-15-950

Bellieny-Rabelo, D., De Oliveira, E.A., Ribeiro, E.S., Costa, E.P., Oliveira, A.E., and Venancio, T.M. (2016). Transcriptome analysis uncovers key regulatory and metabolic aspects of soybean embryonic axes during germination. Sci Rep 6, 36009.10.1038/srep36009

Benedito, V.A., Torres-Jerez, I., Murray, J.D., Andriankaja, A., Allen, S., Kakar, K., Wandrey, M., Verdier, J., Zuber, H., Ott, T., Moreau, S., Niebel, A., Frickey, T., Weiller, G., He, J., Dai, X., Zhao, P.X., Tang, Y., and Udvardi, M.K. (2008). A gene expression atlas of the model legumeMedicago truncatula. The Plant Journal 55, 504-513.10.1111/j.1365313X.2008.03519.x

Bolger, A.M., Lohse, M., and Usadel, B. (2014). Trimmomatic: a flexible trimmer for Illumina sequence data. Bioinformatics 30, 2114-2120.10.1093/bioinformatics/btu170

Bowman, J.L., Smyth, D.R., and Meyerowitz, E.M. (2012). The ABC model of flower development: then and now. Development 139, 4095-4098.10.1242/dev.083972

Chi, Y., Wang, T., Xu, G., Yang, H., Zeng, X., Shen, Y., Yu, D., and Huang, F. (2017). GmAGL1, a MADS-Box Gene from Soybean, Is Involved in Floral Organ Identity and Fruit Dehiscence. Frontiers in Plant Science 8.10.3389/fpls.2017.00175

Conesa, A., Madrigal, P., Tarazona, S., Gomez-Cabrero, D., Cervera, A., Mcpherson, A., Szcześniak, M.W., Gaffney, D.J., Elo, L.L., Zhang, X., and Mortazavi, A. (2016). A survey of best practices for RNA-seq data analysis. Genome Biology 17.10.1186/s13059-016-0881-8

Czechowski, T., Stitt, M., Altmann, T., Udvardi, M.K., and Scheible, W.R. (2005). Genome-wide identification and testing of superior reference genes for transcript normalization in Arabidopsis. Plant Physiol 139, 5-17.10.1104/pp.105.063743

Dash, S., Van Hemert, J., Hong, L., Wise, R.P., and Dickerson, J.A. (2012). PLEXdb: gene expression resources for plants and plant pathogens. Nucleic Acids Res 40, D11941201.10.1093/nar/gkr938

Day, R.C., Herridge, R.P., Ambrose, B.A., and Macknight, R.C. (2008). Transcriptome Analysis of Proliferating Arabidopsis Endosperm Reveals Biological Implications for the Control of Syncytial Division, Cytokinin Signaling, and Gene Expression Regulation. Plant Physiology 148, 1964-1984.10.1104/pp.108.128108

Deshmukh, R., Sonah, H., Patil, G., Chen, W., Prince, S., Mutava, R., Vuong, T., Valliyodan, B., and Nguyen, H.T. (2014). Integrating omic approaches for abiotic stress tolerance in soybean. Frontiers in Plant Science 5.10.3389/fpls.2014.00244

Dey, K.K., Hsiao, C.J., and Stephens, M. (2017). Visualizing the structure of RNA-seq expression data using grade of membership models. PLoS Genet 13, e1006599.10.1371/journal.pgen.1006599 
Dobin, A., Davis, C.A., Schlesinger, F., Drenkow, J., Zaleski, C., Jha, S., Batut, P., Chaisson, M., and Gingeras, T.R. (2013). STAR: ultrafast universal RNA-seq aligner. Bioinformatics 29, 1521.10.1093/bioinformatics/bts635

El-Gebali, S., Mistry, J., Bateman, A., Eddy, S.R., Luciani, A., Potter, S.C., Qureshi, M., Richardson, L.J., Salazar, G.A., Smart, A., Sonnhammer, E.L I., Hirsh, L., Paladin, L., Piovesan, D., Tosatto, S.C e., and Finn, R.D. (2019). The Pfam protein families database in 2019. Nucleic Acids Res 47, D427-D432.10.1093/nar/gky995

Figueroa, P. (2005). Arabidopsis Has Two Redundant Cullin3 Proteins That Are Essential for Embryo Development and That Interact with RBX1 and BTB Proteins to Form Multisubunit E3 Ubiquitin Ligase Complexes in Vivo. The Plant Cell Online 17, 11801195.10.1105/tpc.105.031989

Florea, L., Song, L., and Salzberg, S.L. (2013). Thousands of exon skipping events differentiate among splicing patterns in sixteen human tissues. F1000Research 2, 188.10.12688/f1000research.2-188.v1

Fucile, G., Di Biase, D., Nahal, H., La, G., Khodabandeh, S., Chen, Y., Easley, K., Christendat, D., Kelley, L., and Provart, N.J. (2011). ePlant and the 3D data display initiative: integrative systems biology on the world wide web. PLoS One 6, e15237.10.1371/journal.pone.0015237

Garg, R., and Jain, M. (2013). Transcriptome Analyses in Legumes: A Resource for Functional Genomics. The Plant Genome 6, 0.10.3835/plantgenome2013.04.0011

Gazara, R.K., De Oliveira, E.a.G., Rodrigues, B.C., Nunes Da Fonseca, R., Oliveira, A.E.A., and Venancio, T.M. (2019). Transcriptional landscape of soybean (Glycine max) embryonic axes during germination in the presence of paclobutrazol, a gibberellin biosynthesis inhibitor. Sci Rep 9, 9601.10.1038/s41598-019-45898-2

Goettel, W., Xia, E., Upchurch, R., Wang, M.L., Chen, P., and An, Y.Q. (2014). Identification and characterization of transcript polymorphisms in soybean lines varying in oil composition and content. BMC Genomics 15, 299.10.1186/1471-2164-15-299

Goodstein, D.M., Shu, S., Howson, R., Neupane, R., Hayes, R.D., Fazo, J., Mitros, T., Dirks, W., Hellsten, U., Putnam, N., and Rokhsar, D.S. (2012). Phytozome: a comparative platform for green plant genomics. Nucleic Acids Res 40, D1178-1186.10.1093/nar/gkr944

Griesmann, M., Chang, Y., Liu, X., Song, Y., Haberer, G., Crook, M.B., Billault-Penneteau, B., Lauressergues, D., Keller, J., Imanishi, L., Roswanjaya, Y.P., Kohlen, W., Pujic, P., Battenberg, K., Alloisio, N., Liang, Y., Hilhorst, H., Salgado, M.G., Hocher, V., Gherbi, H., Svistoonoff, S., Doyle, J.J., He, S., Xu, Y., Xu, S., Qu, J., Gao, Q., Fang, X., Fu, Y., Normand, P., Berry, A.M., Wall, L.G., Ane, J.M., Pawlowski, K., Xu, X., Yang, H., Spannagl, M., Mayer, K.F.X., Wong, G.K., Parniske, M., Delaux, P.M., and Cheng, S. (2018). Phylogenomics reveals multiple losses of nitrogen-fixing root nodule symbiosis. Science 361.10.1126/science.aat1743

He, J., Benedito, V.A., Wang, M., Murray, J.D., Zhao, P.X., Tang, Y., and Udvardi, M.K. (2009). The Medicago truncatula gene expression atlas web server. BMC Bioinformatics 10, 441.10.1186/1471-2105-10-441

Hoang, V.L.T., Tom, L.N., Quek, X.C., Tan, J.M., Payne, E.J., Lin, L.L., Sinnya, S., Raphael, A.P., Lambie, D., Frazer, I.H., Dinger, M.E., Soyer, H.P., and Prow, T.W. (2017). RNA-seq reveals 
more consistent reference genes for gene expression studies in human non-melanoma skin cancers. PeerJ 5, e3631.10.7717/peerj.3631

Hu, R., Fan, C., Li, H., Zhang, Q., and Fu, Y.F. (2009). Evaluation of putative reference genes for gene expression normalization in soybean by quantitative real-time RT-PCR. BMC Mol Biol 10, 93.10.1186/1471-2199-10-93

lizumi, T., Luo, J.-J., Challinor, A.J., Sakurai, G., Yokozawa, M., Sakuma, H., Brown, M.E., and Yamagata, T. (2014). Impacts of El Niño Southern Oscillation on the global yields of major crops. Nat Commun 5.10.1038/ncomms4712

Jones, S.I., and Vodkin, L.O. (2013). Using RNA-Seq to profile soybean seed development from fertilization to maturity. PLoS One 8, e59270.10.1371/journal.pone.0059270

Jordan, I.K., Reeb, P.D., Bramardi, S.J., and Steibel, J.P. (2015). Assessing Dissimilarity Measures for Sample-Based Hierarchical Clustering of RNA Sequencing Data Using Plasmode Datasets. PLoS One 10, e0132310.10.1371/journal.pone.0132310

Jung, C.H., Wong, C.E., Singh, M.B., and Bhalla, P.L. (2012). Comparative genomic analysis of soybean flowering genes. PLoS One 7, e38250.10.1371/journal.pone.0038250

Kim, E., Hwang, S., and Lee, I. (2017). SoyNet: a database of co-functional networks for soybeanGlycine max. Nucleic Acids Res 45, D1082-D1089.10.1093/nar/gkw704

Konishi, M., and Yanagisawa, S. (2013). Arabidopsis NIN-like transcription factors have a central role in nitrate signalling. Nat Commun 4, 1617.10.1038/ncomms2621

Krijthe, J.H. (2015). Rtsne: T-Distributed Stochastic Neighbor Embedding using Barnes-Hut Implementation.

Kryuchkova-Mostacci, N., and Robinson-Rechavi, M. (2017). A benchmark of gene expression tissue-specificity metrics. Brief Bioinform 18, 205-214.10.1093/bib/bbw008

Langmead, B., and Salzberg, S.L. (2012). Fast gapped-read alignment with Bowtie 2. Nat Methods 9, 357-359.10.1038/nmeth.1923

Leinonen, R., Akhtar, R., Birney, E., Bonfield, J., Bower, L., Corbett, M., Cheng, Y., Demiralp, F., Faruque, N., Goodgame, N., Gibson, R., Hoad, G., Hunter, C., Jang, M., Leonard, S., Lin, Q., Lopez, R., Maguire, M., Mcwilliam, H., Plaister, S., Radhakrishnan, R., Sobhany, S., Slater, G., Ten Hoopen, P., Valentin, F., Vaughan, R., Zalunin, V., Zerbino, D., and Cochrane, G. (2010). Improvements to services at the European Nucleotide Archive. Nucleic Acids Res 38, D3945.10.1093/nar/gkp998

Li, W.V., and Li, J.J. (2018). Modeling and analysis of RNA-seq data: a review from a statistical perspective. Quantitative Biology 6, 195-209.10.1007/s40484-018-0144-7

Liao, Y., Smyth, G.K., and Shi, W. (2014). featureCounts: an efficient general purpose program for assigning sequence reads to genomic features. Bioinformatics 30, 923930.10.1093/bioinformatics/btt656

Libault, M., Farmer, A., Joshi, T., Takahashi, K., Langley, R.J., Franklin, L.D., He, J., Xu, D., May, G., and Stacey, G. (2010). An integrated transcriptome atlas of the crop model Glycine max, and its use in comparative analyses in plants. Plant $J$ 63, 86-99.10.1111/j.1365313X.2010.04222.x

Liu, P., and Si, Y. (2014). Cluster Analysis of RNA-Sequencing Data. 191-217.10.1007/978-3-31907212-8_10 
Lyne, R., Sullivan, J., Butano, D., Contrino, S., Heimbach, J., Hu, F., Kalderimis, A., Lyne, M., N. Smith, R., Štěpán, R., Balakrishnan, R., Binkley, G., Harris, T., Karra, K., A. T. Moxon, S., Motenko, H., Neuhauser, S., Ruzicka, L., Cherry, M., Richardson, J., Stein, L., Westerfield, M., Worthey, E., and Micklem, G. (2015). Cross-organism analysis using InterMine. genesis 53, 547-560.10.1002/dvg.22869

Marini, F., and Binder, H. (2019). pcaExplorer: an R/Bioconductor package for interacting with RNA-seq principal components. BMC Bioinformatics 20.10.1186/s12859-019-2879-1

Meinke, D.W. (2019). Genome-wide identification of EMBRYO-DEFECTIVE (EMB) genes required for growth and development in Arabidopsis. New Phytol.10.1111/nph.16071

Moharana, K.C., and Venancio, T.M. (2019). Polyploidization events shaped the transcription factor repertoires in legumes (Fabaceae). bioRxiv, 849778.10.1101/849778

Mortazavi, A., Williams, B.A., Mccue, K., Schaeffer, L., and Wold, B. (2008). Mapping and quantifying mammalian transcriptomes by RNA-Seq. Nat Methods 5, 621628.10.1038/nmeth.1226

Niknafs, Y.S., Pandian, B., Iyer, H.K., Chinnaiyan, A.M., and Iyer, M.K. (2017). TACO produces robust multisample transcriptome assemblies from RNA-seq. Nat Methods 14, 6870.10.1038/nmeth.4078

O'rourke, J.A., Graham, M.A., and Whitham, S.A. (2017). Soybean Functional Genomics: Bridging the Genotype-to-Phenotype Gap. 151-170.10.1007/978-3-319-64198-0_10

Pertea, M., Pertea, G.M., Antonescu, C.M., Chang, T.C., Mendell, J.T., and Salzberg, S.L. (2015). StringTie enables improved reconstruction of a transcriptome from RNA-seq reads. Nat Biotechnol 33, 290-295.10.1038/nbt.3122

Po-Yen, W., Phan, J.H., Fengfeng, Z., and Wang, M.D. (2011). Evaluation of normalization methods for RNA-Seq gene expression estimation. 50-57.10.1109/bibmw.2011.6112354

Ritchie, M.E., Phipson, B., Wu, D., Hu, Y., Law, C.W., Shi, W., and Smyth, G.K. (2015). limma powers differential expression analyses for RNA-sequencing and microarray studies. Nucleic Acids Res 43, e47-e47.10.1093/nar/gkv007

Robinson, J.T., Thorvaldsdottir, H., Winckler, W., Guttman, M., Lander, E.S., Getz, G., and Mesirov, J.P. (2011). Integrative genomics viewer. Nat Biotechnol 29, 24-26.10.1038/nbt.1754

Robinson, M.D., and Oshlack, A. (2010). A scaling normalization method for differential expression analysis of RNA-seq data. Genome Biology 11, R25.10.1186/gb-2010-11-3-r25

Rocchi, V., Janni, M., Bellincampi, D., Giardina, T., and D'ovidio, R. (2012). Intron retention regulates the expression of pectin methyl esterase inhibitor (Pmei) genes during wheat growth and development. Plant Biol (Stuttg) 14, 365-373.10.1111/j.1438-8677.2011.00508.x

Roy, S., Liu, W., Nandety, R.S., Crook, A.D., Mysore, K.S., Pislariu, C.I., Frugoli, J.A., Dickstein, R., and Udvardi, M.K. (2019). Celebrating 20 years of genetic discoveries in legume nodulation and symbiotic nitrogen fixation. Plant Cell, tpc.00279.02019.10.1105/tpc.19.00279 J.J., Cheng, J., Xu, D., Hellsten, U., May, G.D., Yu, Y., Sakurai, T., Umezawa, T., Bhattacharyya, M.K., Sandhu, D., Valliyodan, B., Lindquist, E., Peto, M., Grant, D., Shu, S., Goodstein, D., Barry, K., Futrell-Griggs, M., Abernathy, B., Du, J., Tian, Z., Zhu, L., Gill, N., Joshi, T., Libault, M., Sethuraman, A., Zhang, X.C., Shinozaki, K., Nguyen, H.T., Wing, R.A., Cregan, P., Specht, 
J., Grimwood, J., Rokhsar, D., Stacey, G., Shoemaker, R.C., and Jackson, S.A. (2010). Genome sequence of the palaeopolyploid soybean. Nature 463, 178-183.10.1038/nature08670

Schwacke, R., Ponce-Soto, G.Y., Krause, K., Bolger, A.M., Arsova, B., Hallab, A., Gruden, K., Stitt, M., Bolger, M.E., and Usadel, B. (2019). MapMan4: A Refined Protein Classification and Annotation Framework Applicable to Multi-Omics Data Analysis. Molecular Plant 12, 879892.10.1016/j.molp.2019.01.003

Severin, A.J., Woody, J.L., Bolon, Y.T., Joseph, B., Diers, B.W., Farmer, A.D., Muehlbauer, G.J., Nelson, R.T., Grant, D., Specht, J.E., Graham, M.A., Cannon, S.B., May, G.D., Vance, C.P., and Shoemaker, R.C. (2010). RNA-Seq Atlas of Glycine max: a guide to the soybean transcriptome. BMC Plant Biol 10, 160.10.1186/1471-2229-10-160

Sinharoy, S., Torres-Jerez, I., Bandyopadhyay, K., Kereszt, A., Pislariu, C.I., Nakashima, J., Benedito, V.A., Kondorosi, E., and Udvardi, M.K. (2013). The $\mathrm{C} 2 \mathrm{H} 2$ transcription factor regulator of symbiosome differentiation represses transcription of the secretory pathway gene VAMP721a and promotes symbiosome development in Medicago truncatula. Plant Cell 25, 3584-3601.10.1105/tpc.113.114017

Smalle, J., and Vierstra, R.D. (2004). The Ubiquitin 26s Proteasome Proteolytic Pathway. Annual Review of Plant Biology 55, 555-590.10.1146/annurev.arplant.55.031903.141801

Soltis, D.E., Chanderbali, A.S., Kim, S., Buzgo, M., and Soltis, P.S. (2007). The ABC Model and its Applicability to Basal Angiosperms. Annals of Botany 100, 155-163.10.1093/aob/mcm117

Thimm, O., Bläsing, O., Gibon, Y., Nagel, A., Meyer, S., Krüger, P., Selbig, J., Müller, L.A., Rhee, S.Y., and Stitt, M. (2004). mapman: a user-driven tool to display genomics data sets onto diagrams of metabolic pathways and other biological processes. The Plant Journal 37, 914939.10.1111/j.1365-313X.2004.02016.x

Vernié, T., Moreau, S., De Billy, F., Plet, J., Combier, J.-P., Rogers, C., Oldroyd, G., Frugier, F., Niebel, A., and Gamas, P. (2008). EFD Is an ERF Transcription Factor Involved in the Control of Nodule Number and Differentiation in Medicago truncatula. Plant Cell 20, 26962713.10.1105/tpc.108.059857

Wagner, G.P., Kin, K., and Lynch, V.J. (2012). Measurement of mRNA abundance using RNA-seq data: RPKM measure is inconsistent among samples. Theory in Biosciences 131, 281285.10.1007/s12064-012-0162-3

Wang, L., Wang, S., and Li, W. (2012). RSeQC: quality control of RNA-seq experiments. Bioinformatics 28, 2184-2185.10.1093/bioinformatics/bts356

Weller, J.L., and Ortega, R.L. (2015). Genetic control of flowering time in legumes. Frontiers in Plant Science 6.10.3389/fpls.2015.00207

Wormit, A., and Usadel, B. (2018). The Multifaceted Role of Pectin Methylesterase Inhibitors (PMEls). International Journal of Molecular Sciences 19, 2878.10.3390/ijms19102878

Wu, Z., Wang, M., Yang, S., Chen, S., Chen, X., Liu, C., Wang, S., Wang, H., Zhang, B., Liu, H., Qin, R., and Wang, X. (2019). A global coexpression network of soybean genes gives insights into the evolution of nodulation in nonlegumes and legumes. New Phytologist.10.1111/nph.15845

Yanai, I., Benjamin, H., Shmoish, M., Chalifa-Caspi, V., Shklar, M., Ophir, R., Bar-Even, A., HornSaban, S., Safran, M., Domany, E., Lancet, D., and Shmueli, O. (2004). Genome-wide midrange 
721 transcription profiles reveal expression level relationships in human tissue specification.

722 Bioinformatics 21, 650-659.10.1093/bioinformatics/bti042

723 Yim, A.K., Wong, J.W., Ku, Y.S., Qin, H., Chan, T.F., and Lam, H.M. (2015). Using RNA-Seq Data to

724 Evaluate Reference Genes Suitable for Gene Expression Studies in Soybean. PLoS One 10,

725 e0136343.10.1371/journal.pone.0136343

726 Zhao, S., Zhang, Y., Gordon, W., Quan, J., Xi, H., Du, S., Von Schack, D., and Zhang, B. (2015).

727 Comparison of stranded and non-stranded RNA-seq transcriptome profiling and investigation

728 of gene overlap. BMC Genomics 16.10.1186/s12864-015-1876-7

729 Zhao, T., Holmer, R., De Bruijn, S., Angenent, G.C., Van Den Burg, H.A., and Schranz, M.E. (2017).

$730 \quad$ Phylogenomic Synteny Network Analysis of MADS-Box Transcription Factor Genes Reveals

731 Lineage-Specific Transpositions, Ancient Tandem Duplications, and Deep Positional

732 Conservation. Plant Cell 29, 1278-1292.10.1105/tpc.17.00312

733

734 
bioRxiv preprint doi: https://doi.org/10.1101/2019.12.23.886853; this version posted December 23, 2019. The copyright holder for this preprint (which was not certified by peer review) is the author/funder, who has granted bioRxiv a license to display the preprint in perpetuity. It is made available under aCC-BY-NC-ND 4.0 International license.

\section{Tables}

736

737 Table 1: Tissue-specific transcription factors.

\begin{tabular}{|c|c|c|c|c|c|c|c|c|c|c|c|c|}
\hline $\begin{array}{l}\text { Transcription } \\
\text { factor family }\end{array}$ & 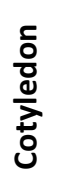 & $\begin{array}{l}\text { ह } \\
\frac{2}{0} \\
\frac{0}{n} \\
\frac{0}{0} \\
\frac{c}{\omega}\end{array}$ & $\begin{array}{l}\frac{1}{0} \\
\frac{0}{3}\end{array}$ & 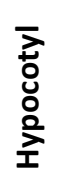 & 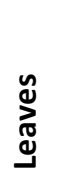 & $\begin{array}{l}\frac{0}{2} \\
\frac{7}{0} \\
\text { Z }\end{array}$ & 용 & $\begin{array}{l}+ \\
\stackrel{0}{0} \\
\stackrel{\alpha}{ }\end{array}$ & ర్d & $\begin{array}{l}\stackrel{t}{0} \\
\frac{o}{n}\end{array}$ & 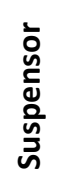 & $\begin{array}{l}\bar{\pi} \\
\stackrel{0}{0}\end{array}$ \\
\hline MYB & & 5 & 8 & 7 & 2 & & 1 & 2 & 1 & & 1 & 27 \\
\hline ERF & & 1 & 1 & 10 & & 3 & & 3 & & & 2 & 20 \\
\hline $\mathrm{C} 2 \mathrm{H} 2$ & & 6 & & 1 & & 6 & 2 & 2 & & & 4 & 21 \\
\hline NAC & & & & 2 & & 1 & & & 1 & & 4 & 8 \\
\hline bHLH & 2 & 1 & & 2 & & & & 4 & & & & 9 \\
\hline WRKY & & & & 6 & & & & 2 & & & 2 & 10 \\
\hline MYB_related & & 2 & 1 & 1 & & & & & & & & 4 \\
\hline LBD & & & 1 & & & & & 1 & & & 1 & 3 \\
\hline G2-like & 1 & 1 & & & & & & 1 & & & & 3 \\
\hline NF-YB & & 1 & & & & 2 & & & & & & 3 \\
\hline M-type & & 2 & & & & 1 & & & & & & 3 \\
\hline MIKC & & & 8 & & & & & 1 & & & & 9 \\
\hline HD-ZIP & & 2 & & & & & & & & & 2 & 4 \\
\hline GRAS & & & & 1 & & 2 & & & & & & 3 \\
\hline bZIP & & 2 & & & & 4 & & & & & & 6 \\
\hline B3 & & 2 & & & & & & & & & 2 & 4 \\
\hline AP2 & & & & & & 2 & & & & & 1 & 3 \\
\hline ZF-HD & & 2 & & & & & & & & & & 2 \\
\hline YABBY & & & 1 & & & & & & & & & 1 \\
\hline wOX & & & & & & & & & & & 3 & 3 \\
\hline SRS & & & & & & 1 & & & & & & 1 \\
\hline SBP & & & & & & & & & & 1 & & 1 \\
\hline NZZ/SPL & & 2 & & & & & & & & & & 2 \\
\hline Nin-like & & & & & & 6 & & & & & & 6 \\
\hline NF-YC & & 3 & & & & & & & & & & 3 \\
\hline NF-YA & & & & & & 1 & & & & & & 1 \\
\hline HSF & & & & 1 & & & & & & & & 1 \\
\hline GRF & & & & & & & & & & 1 & & 1 \\
\hline GATA & 1 & & & & & & & & & & & 1 \\
\hline Dof & & & & 1 & & & & & & & & 1 \\
\hline CPP & & 1 & & & & & & & & & & 1 \\
\hline $\mathrm{C} 3 \mathrm{H}$ & & 3 & & & & & & & & & & 3 \\
\hline Total & 4 & 36 & 20 & 32 & 2 & 29 & 3 & 16 & 2 & 2 & 22 & 168 \\
\hline
\end{tabular}

738

739 
bioRxiv preprint doi: https://doi.org/10.1101/2019.12 23 886853: this version posted December 23,2019 . The copyright holder for this preprint (which was not certified by peer review) is the author/funder, who has granted bioRxiv a license to display the preprint in perpetuity. It is made available under aCC-BY-NC-ND 4.0 International license.

740 Table 2: Number of transcripts in each transcript-classification code defined by 741 GffCompare.

\begin{tabular}{lll}
\hline Class code & Description & \# of transfrags \\
\hline $\mathbf{~}$ & Complete, exact match of intron chain & 70,963 \\
$\mathbf{j}$ & Multi-exon with at least one exon junction match & 3256 \\
$\mathbf{c}$ & Contained in reference (intron compactable) & 78 \\
$\mathbf{e}$ & Single exon transfrag partially covering intron, possible pre-mRNA & 70 \\
$\mathbf{k}$ & Containment of reference (reverse containment) & 69 \\
$\mathbf{u}$ & Unknown, intergenic & 23 \\
$\mathbf{0}$ & Other same strand overlap with reference exon & 23 \\
$\mathbf{x}$ & Exonic overlap on opposite strand & 4 \\
$\mathbf{p}$ & Possible polymerase run-on (no actual overlap) & 4 \\
\hline
\end{tabular}

742

743

744 Table 3: Number of alternative splicing events (AS). The first column illustrates the 745 possible AS isoforms. The boxes represent exons and lines connect adjacent exons in the 746 mature transcript.

\begin{tabular}{|c|c|c|}
\hline Exon junctions & Event type & $\begin{array}{l}\text { Number } \\
\text { of events }\end{array}$ \\
\hline & Exon skipping (SKIP) & 218 \\
\hline & $\begin{array}{l}\text { Multiple exon skipping } \\
\text { (MSKIP) }\end{array}$ & 40 \\
\hline & $\begin{array}{l}\text { Retention of single or } \\
\text { multiple introns (IR/MIR) }\end{array}$ & 190 \\
\hline & $\begin{array}{l}\text { Alternative transcript start } \\
\text { (TSS) }\end{array}$ & 2831 \\
\hline & $\begin{array}{l}\text { Alternative transcript } \\
\text { termination (TTS) }\end{array}$ & 2761 \\
\hline & Alternative exon ends ( $\mathrm{AE}$ ) & 542 \\
\hline & Total & 6582 \\
\hline
\end{tabular}


bioRxiv preprint doi: https://doi.org/10.1101/2019.12.23 886853; this version posted December 23, 2019. The copyright holder for this preprint (which was not certified by peer review) is the author/funder, who has granted bioRxiv a license to display the preprint in perpetuity. It is made available under aCC-BY-NC-ND 4.0 International license.

749

750

751

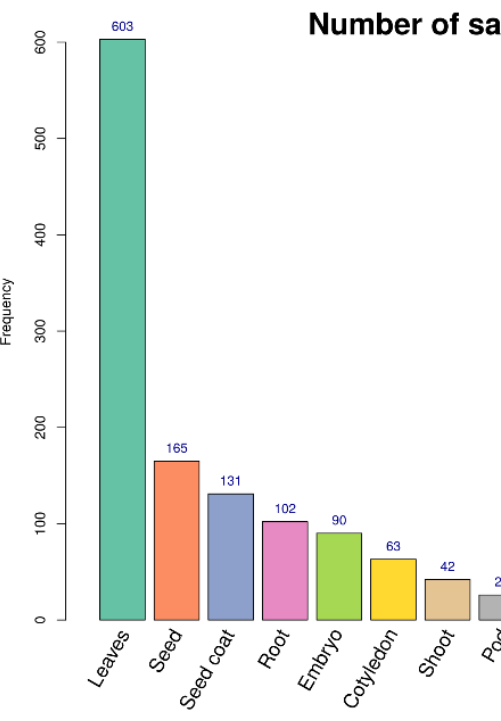

\section{Figures}

.
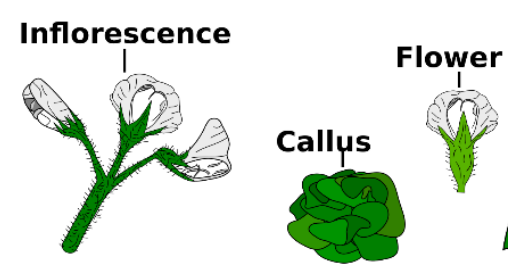

752

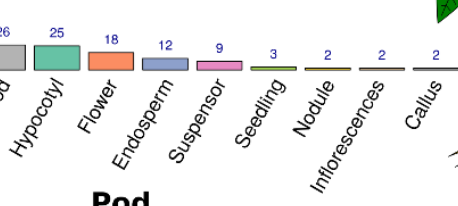

Pod
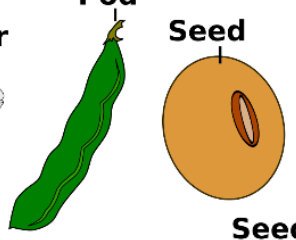

Seed Coat
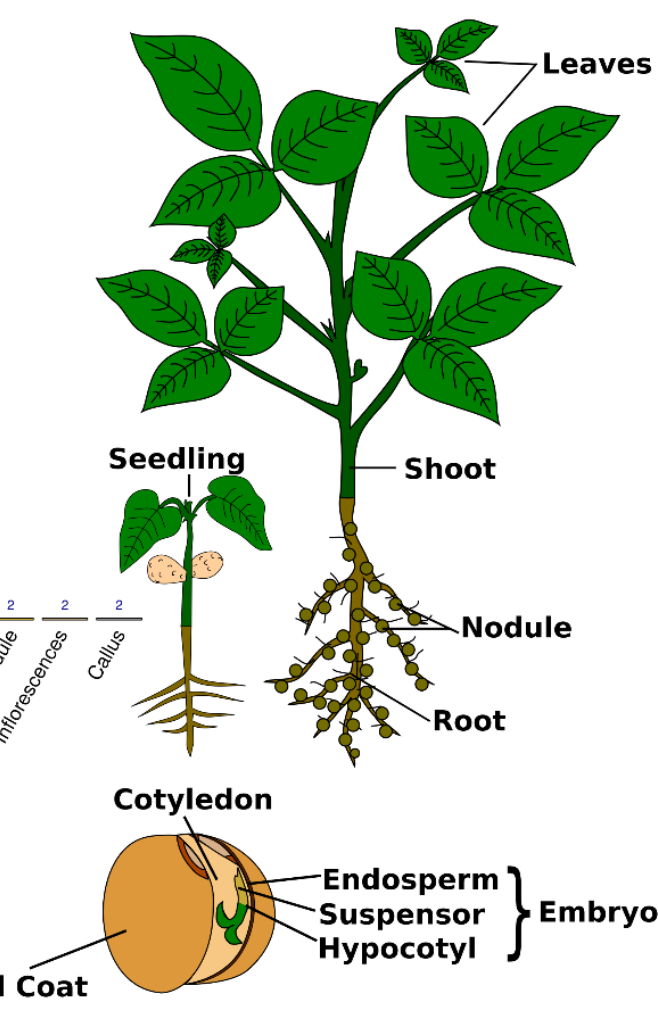

Cotyledon

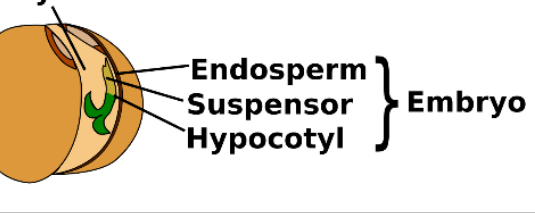

753 Figure 1: Number of samples analyzed in this study and a graphical representation of each 754 tissue. 
bioRxiv preprint doi: https://doi.org/10.1101/2019.12.23.886853; this version posted December 23, 2019. The copyright holder for this preprint (which was not certified by peer review) is the author/funder, who has granted bioRxiv a license to display the preprint in perpetuity. It is made available under aCC-BY-NC-ND 4.0 International license.

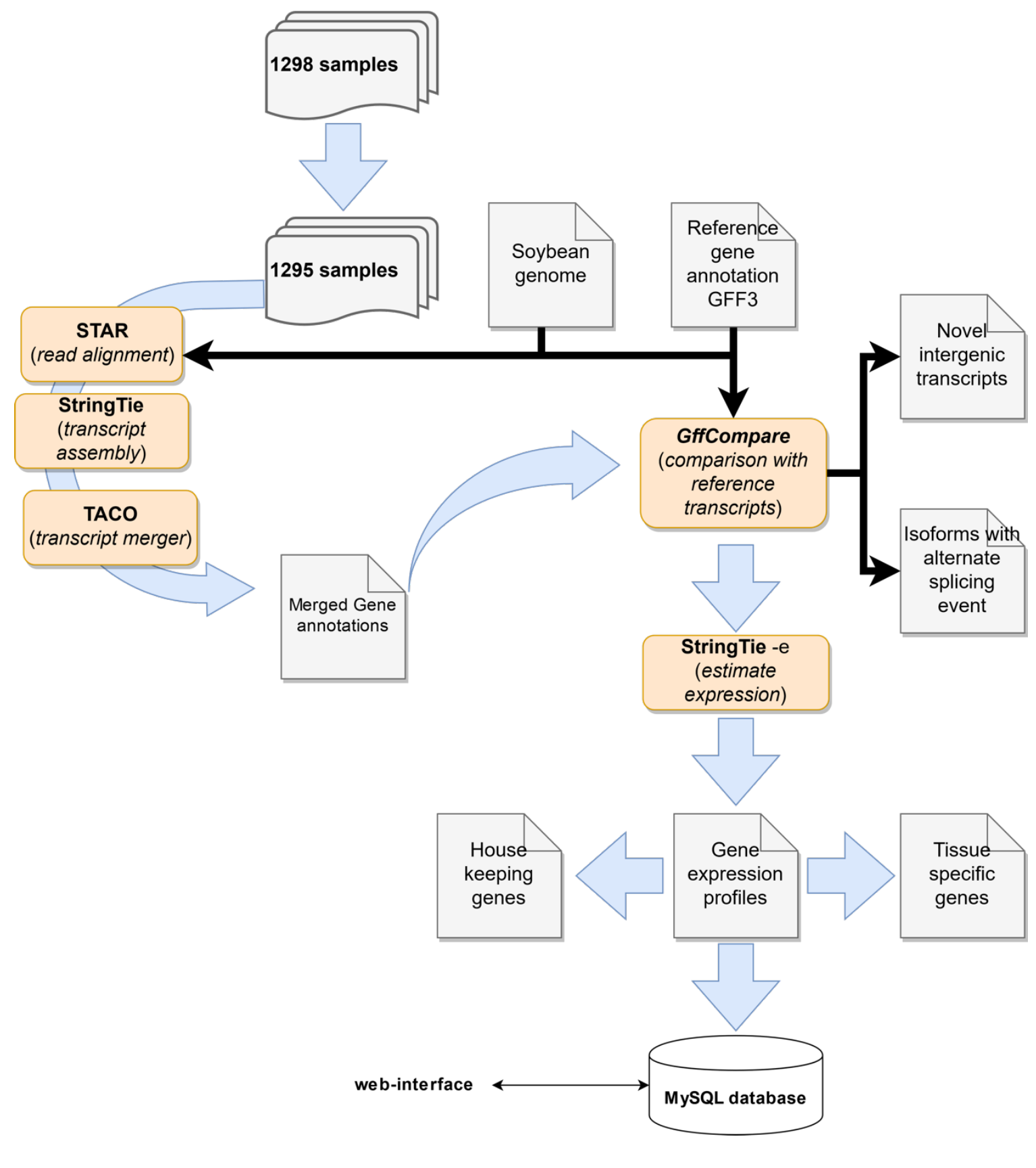

758 Figure 2: Pipeline used to create the soybean RNA-Seq atlas. 


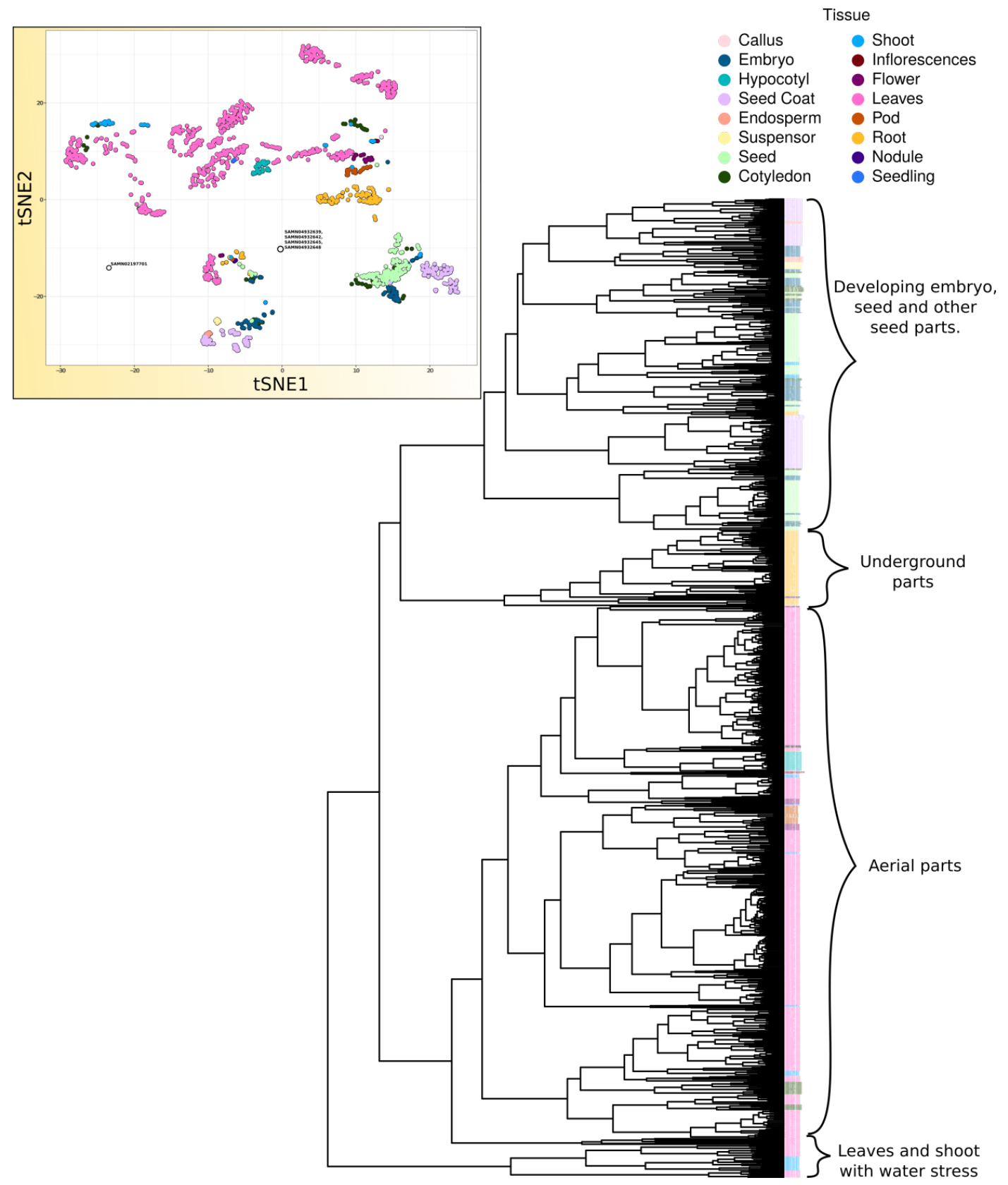

762 Figure 3: Hierarchical clustering of samples using their transcriptional profiles. Per gene

763 raw read counts were used to perform hierarchical clustering using the R function hclust()

764 with default parameters. Samples were grouped into three major clades: aerial,

765 underground, and seed-embryo related. A minor group of samples containing drought-

766 stress-related leaves and shoots was also identified. The upper-left panel shows the

767 sample clustering using t-SNE. Five samples (four from shoot: SAMN04932642,

768 SAMN04932648, SAMN04932639, SAMN04932645 and one from root: SAMN02197701),

769 labeled in the inside plot, showed a very unexpected clustering patterns and were

770 excluded from further analysis. An interactive 3D version of the t-SNE sample clustering

771 is available at http://venanciogroup.uenf.br/resources/. 

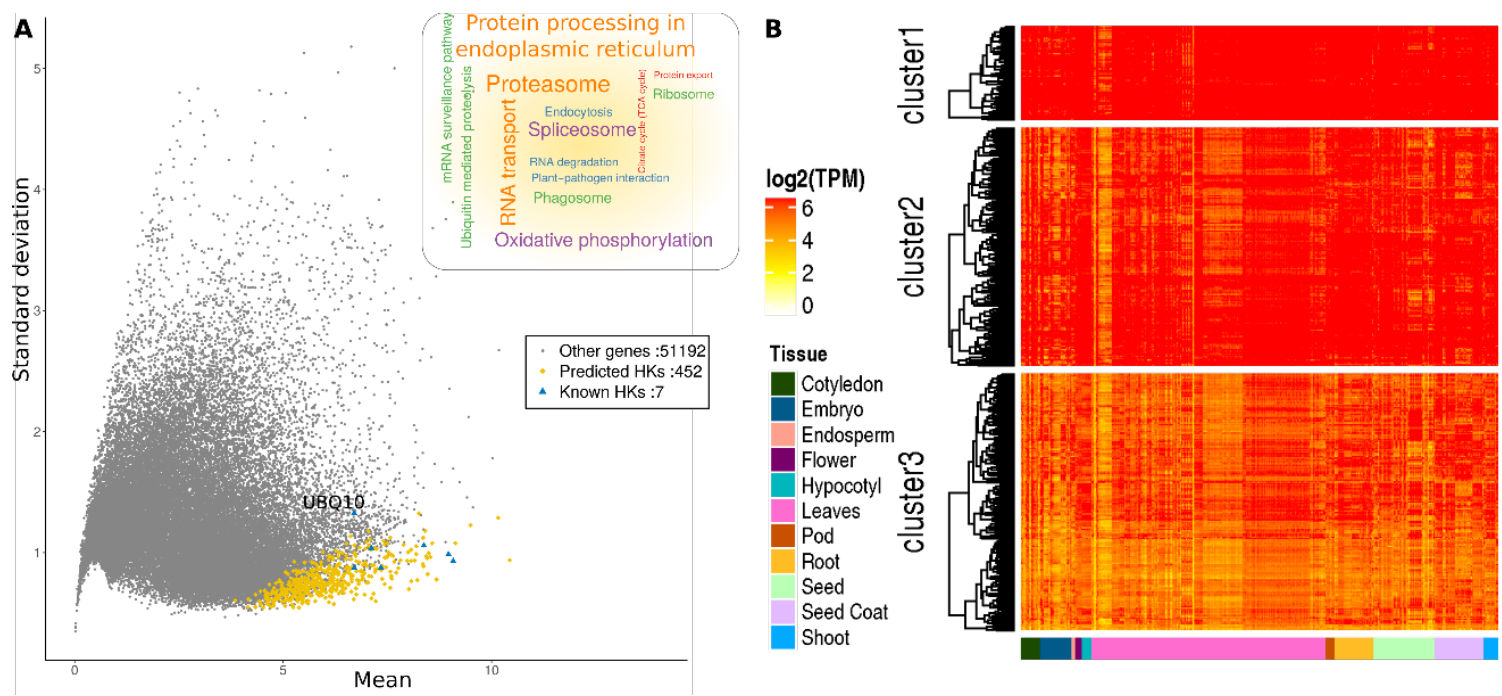

774 Figure 4: Global gene expression patterns of the housekeeping genes. A. Scatter plot of 775 mean vs standard deviation showing uniform and stable expression of 452 housekeeping 776 (HK) genes. The gray dots represent all the non-HK expressed genes (TPM $\geq 1$ in at least 777 one sample). The word cloud represents KEGG pathways enriched in HK genes ( $p$-value < 778 0.05). B. Global expression patterns of HK genes. Three main clusters were found with K779 means clustering, which were then hierarchically clustered. 
bioRxiv preprint doi: https://doi.org/10.1101/2019.12.23.886853; this version posted December 23, 2019. The copyright holder for this preprint

(which was not certified by peer review) is the author/funder, who has granted bioRxiv a license to display the preprint in perpetuity. It is made available under aCC-BY-NC-ND 4.0 International license.

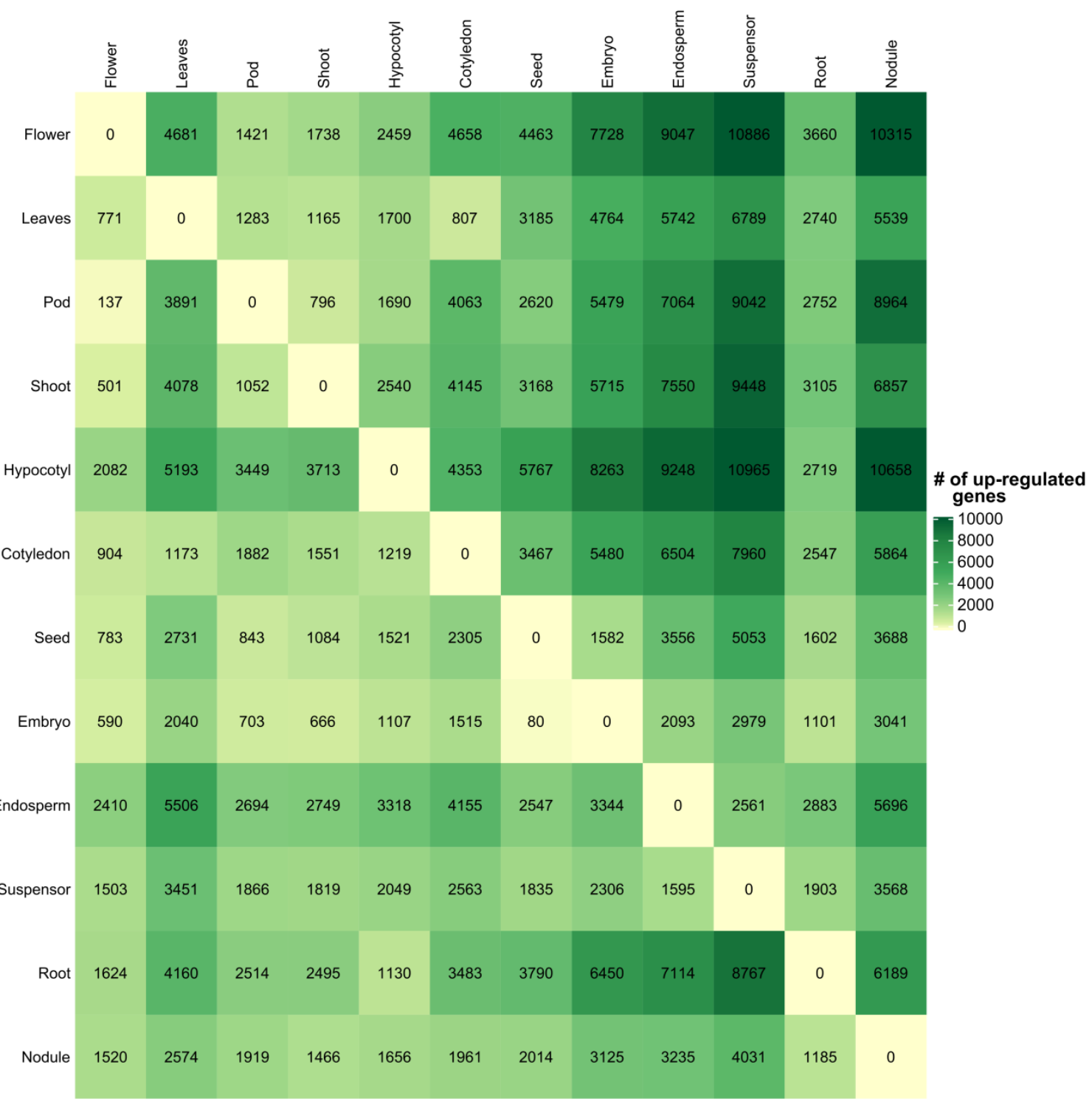

782 Figure 5: Heatmap showing the number of up-regulated genes in the tissues from the 783 rows when compared with those from the columns. Gene up-regulation was determined 784 by using a $\log _{2}$ (fold-change) $\geq 2$ and adjusted $p$-value $\leq 0.05$ using the moderated $t$ 785 statistic in the limma package. 
bioRxiv preprint doi: https://doi.org/10.1101/2019.12.23 886853; this version posted December 23, 2019. The copyright holder for this preprint (which was not certified by peer review) is the author/funder, who has granted bioRxiv a license to display the preprint in perpetuity. It is made available under aCC-BY-NC-ND 4.0 International license.

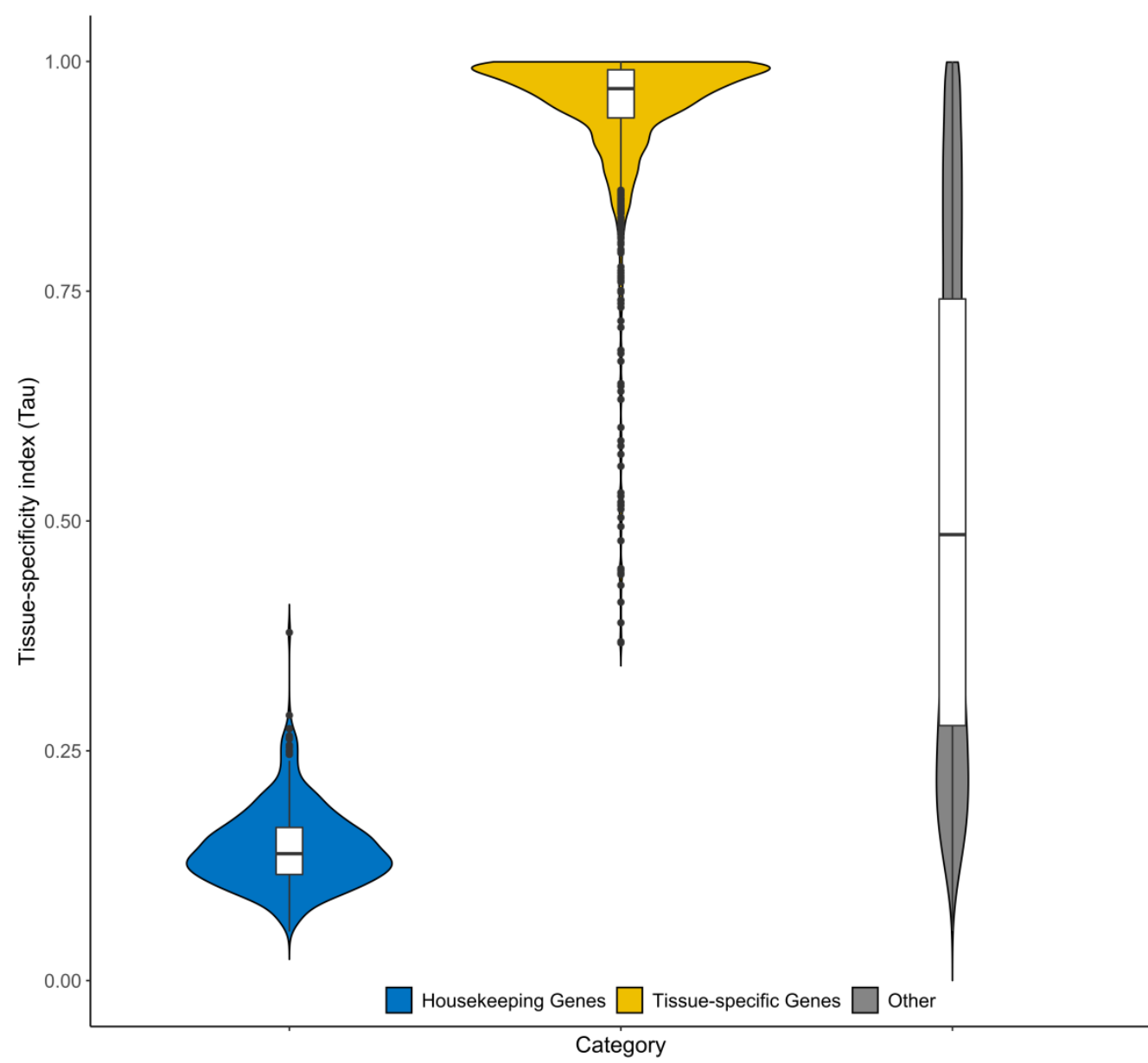

787 Figure 6: Violin plot showing the distribution of Tau indexes of housekeeping, tissue-specific, and 788 the remaining genes. Tau values range between 0 and 1, with low values indicating a stable and 789 constitutive expression and higher values supporting tissue-specificity. 
bioRxiv preprint doi: https://doi.org/10.1101/2019.12.23.886853; this version posted December 23, 2019. The copyright holder for this preprint (which was not certified by peer review) is the author/funder, who has granted bioRxiv a license to display the preprint in perpetuity. It is made available under aCC-BY-NC-ND 4.0 International license.

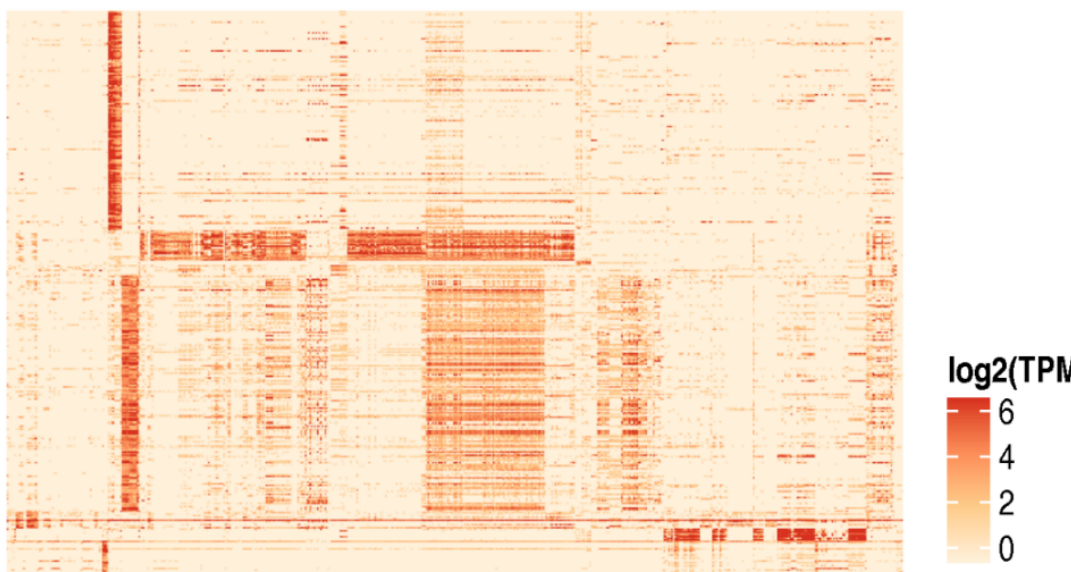

Tissue

Callus

Cotyledon

Embryo

Endosperm

Flower

Hypocotyl

Inflorescences

Leaves

Nodule

Pod

Root

Seed

Seed Coat

Seedling

Shoot

Suspensor

791 Figure 7: Global transcriptional patterns of tissue-specific genes. Expression values are

792 represented as $\log _{2}$ (TPM) values in 1243 samples. 
bioRxiv preprint doi: https://doi.org/10.1101/2019.12.23.886853; this version posted December 23, 2019. The copyright holder for this preprint (which was not certified by peer review) is the author/funder, who has granted bioRxiv a license to display the preprint in perpetuity. It is made available under aCC-BY-NC-ND 4.0 International license.

A

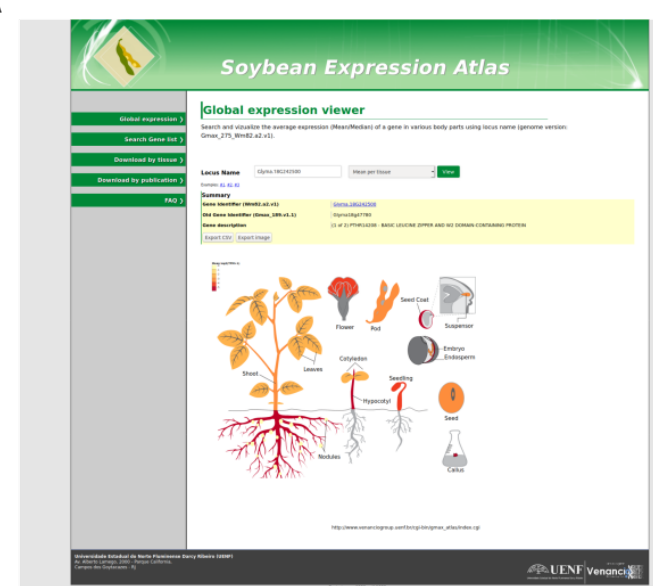

B

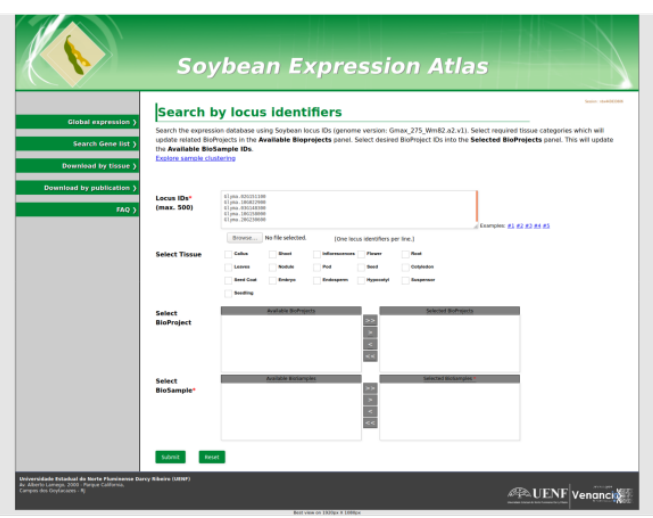

794

Figure 8: Web interface to browse and download the expression data analyzed in this

795 study. A. Users can search, visualize and download average expression levels in each 796 tissue or; B retrieve expression values in batch in particular samples, tissues, or BioProjects. This resource is available at: http://venanciogroup.uenf.br/resources/. 